\title{
Low Temperature Pyrocarbons: A Review
}

\author{
Xavier Bourrat, ${ }^{* \#}$ Francis Langlais, Georges Chollon and Gérard Louis Vignoles
}

Laboratoire des Composites Thermo-Structuraux, Université Bordeaux 1, 3 Allée de la Boétie 33600 Pessac, France

\begin{abstract}
Este artigo é uma síntese das pesquisas recentes na área dos pirocarbonos. Pirocarbono é uma forma de carbono preparada por deposição química em substratos quentes (acima de $900{ }^{\circ} \mathrm{C}$ ) mediante pirólise de hidrocarbonetos. Aplicações se encontram nas áreas de materiais compósitos termostruturais, de reatores nucleares ou de biomateriais. Muito recentemente, um avanço importante foi obtido na compreensão dos processos de crescimento. Uma classificação dos pirocarbonos de baixa temperatura é apresentada, que se fundamenta na medição da quantia de defeitos e do grau de anisotropia, fazendo uso da espectroscopia Raman. Ela traz uma relacão bem estabelecida entre mecanismos de crescimento, estrutura e propriedades dos pirocarbonos.
\end{abstract}

This article is a synthetic survey of the recent researches in the field of pyrocarbons. Pyrocarbon is the form of carbon which deposits on hot surfaces above $900^{\circ} \mathrm{C}$ by cracking of hydrocarbons. Applications are in the fields of composite materials, nuclear reactors or biomaterials. Very recently, an important step was reached concerning the understanding of the growth processes. A classification of the low temperature pyrocarbons is introduced. It is based on the measure of carbon defects and anisotropy, using Raman spectroscopy. It provides a comprehensive relationship between growth mechanisms, structure and properties of pyrocarbons.

Keywords: pyrocarbon, Raman spectroscopy, anisotropy, transmission electron microscopy

\section{Introduction}

What is exactly a pyrolytic carbon or pyrocarbon? If a hydrocarbon is carried above its equilibrium conditions (pressure and temperature) two types of carbon may form. It is either a black powder within the gas, called carbon black or soot, or a deposit, directly on the furnace wall, the pyrocarbon (or even both at the same time). To some extent, there is an analogy with the familiar phenomena of snow and frost formation: gas phase nucleation yields snow and heterogeneous nucleation on a substrate and subsequent growth gives frost.

Pyrocarbons can be deposited at temperatures higher than $2000{ }^{\circ} \mathrm{C}$ for seal-coatings. ${ }^{1}$ The process is commonly defined as CVD for chemical vapour deposition (CVI for infiltration). ${ }^{2}$ As far as CVI is concerned, cracking reactions are conducted in order to avoid carbon black nucleation by lowering the pressure down to 1 to $10 \mathrm{kPa}$ and the temperature around $1000{ }^{\circ} \mathrm{C}$. These conditions

*e-mail: Xavier.Bourrat@univ-orleans.fr

"Present Adress: Institut des Sciences de la Terre d'Orléans, Université of Orléans-CNRS, Geosciences BP 6759, 45067 Orléans Cedex 2, France favour mass transfer with respect to chemical deposition; consequently the homogeneity of the deposit within a preform is enhanced. ${ }^{3}$

Nowadays pyrocarbons are used mainly in three different industries. The first industry in volume is the carbon/carbon composite industry. ${ }^{4}$ These materials are developed to withstand mechanical stresses at very high temperatures. They are aircraft brake disks, as shown on Figure 1, exit cones and nozzles for rocket motors or nose shields for strategic missiles, etc. Basically the process involves a carbon fiber perform, which is infiltrated by CVI as shown on Figure 2.

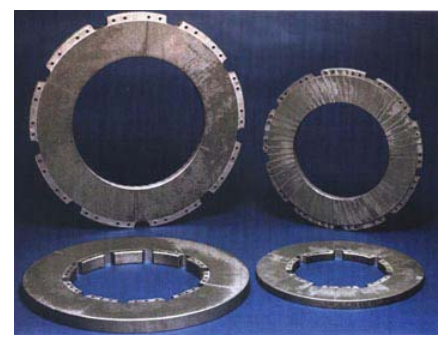

Figure 1. Aircraft brake disks (rotor and stator) made of carbon fiberreinforced pyrocarbon. 


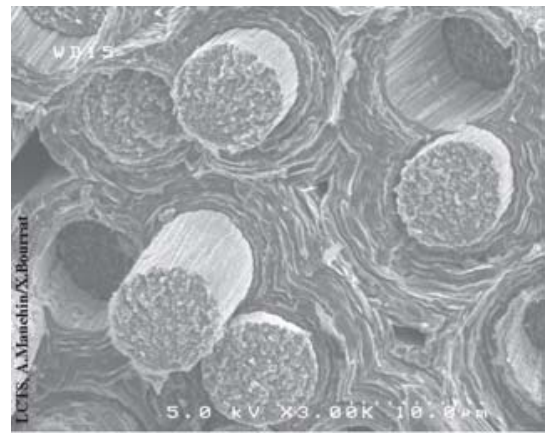

Figure 2. Carbon/carbon composite:carbon fiber-reinforced pyrocarbon (SEM picture of a failure surface).

The other area, with a high added value, concerns the heart valves or the small bone prosthesis (Figure 3). Carbon is biocompatible: it forms a tight coating with an antithrombosis behavior. As a result the contact with blood is excellent. This pyrocarbon is deposited by fluidized bed CVD, at high temperature $\left(1300{ }^{\circ} \mathrm{C}\right)$ starting up with a reactive blend: acetylene/propylene, instead of natural gas.

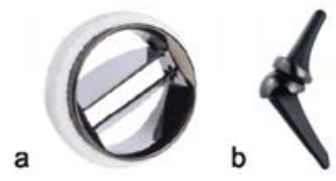

Figure 3. a) Graphite heart valve coated with isotropic pyrocarbon. b) Small joint prosthesis; isotropic pyrocarbon has an excellent contact with cartilage and osteoarthritis.

Finally, the third application area of pyrocarbon deals with the nuclear reactors of the future: high temperature reactors (HTR). The fourth generation of reactors will use this type of isotropic pyrocarbon. ${ }^{5}$ In this case the pyrocarbon plays a role of confinement barrier for fission radioelements. It is processed as a multilayer associated with silicon carbide as shown on Figure 4.

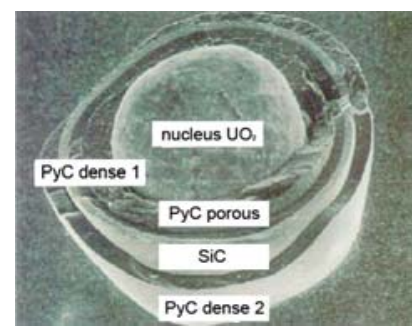

Figure 4. Nuclear fuel particle (diameter: 400 to $600 \mu \mathrm{m}$ ) coated with a multilayer of porous pyrocarbon (PyC buffer), dense pyrocarbons (dense $\mathrm{PyC})$ and silicon carbide ( $\mathrm{SiC})$.

\section{Recent Research Trends on Pyrocarbons}

During the last decades, researches were conducted following two different routes. The first research field was dealing with chemical processing. New processes were developed as the film-boiling process at the French CEA, ${ }^{6}$ the pressure pulsed-CVI at LCTS,${ }^{7}$ the thermalgradient CVI, ${ }^{8}$ or the forced-flux in the US. ${ }^{9}$ The second research area concerned the understanding of the chemical reactions, the cristallo-chemistry and their modelling. It was essentially carried out in France and Germany. ${ }^{10}$ In France, the essential of research was carried out in the LCTS of Bordeaux and the LCSR of Orleans (laboratory for Combustion and Reactive Systems). LCTS is a joint-laboratory of CNRS and Bordeaux University along with CEA and Snecma, where the different specialists are all working on the same materials: experimental chemistry, modelling, crystallography as well as mechanical and thermal properties.

\subsection{Modelling of the reactions during pyrolysis}

Modelling hydrocarbons pyrolysis reactions to grow pyrocarbon is in a first time, very similar to that of incomplete combustion for environmental concerns. The later are developed in the Department of Physics and Chemistry of Reactions (DCPR) in Nancy Polytechnical Institute, France, as well as in LCTS, and different places in the world. The first step in this field is an exhaustive compilation of all the possible elementary reactions. Then, a sensitivity analysis enables to retain only the main reactions in the conditions of interest. At the end of this process, there are still 50 species and 185 reactions in the mechanism. ${ }^{11}$ Following this approach, maturation

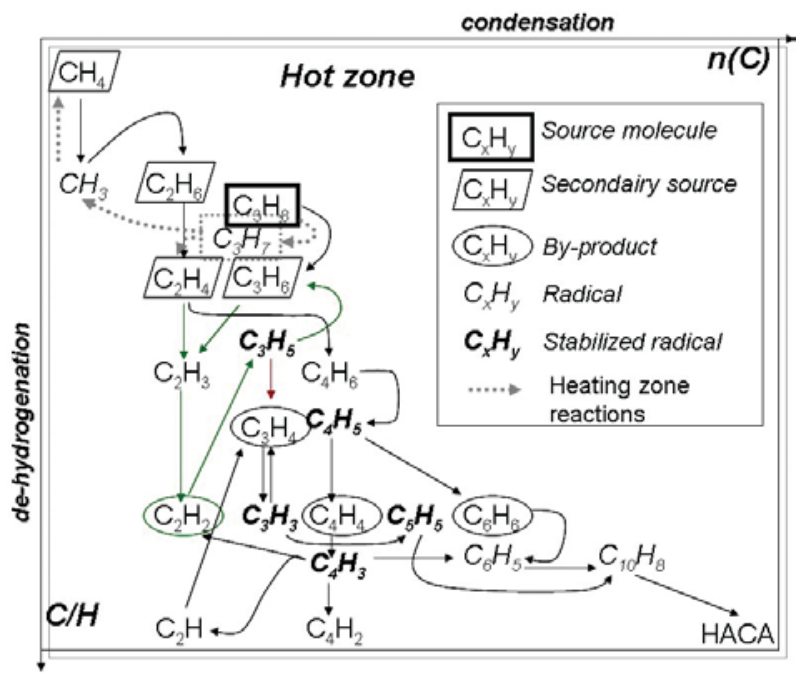

Figure 5. Reaction schemes of dehydrogenation and condensation during the cracking of propane for longer and longer residence time in the hot zone of the furnace; the final step being the HACA process (hydrogen abstraction, condensation of acetylene). Adaptation from Reference 20. 
schemes could be proposed and validated, as illustrated in Figure 5. In the case of pure propane as a precursor gas, there are routes displaying a close interaction of dehydrogenation and condensation of molecules, finishing with the HACA mechanism (Hydrogen Abstraction, Condensation of Acetylene), responsible for PAH (Polycyclic Aromatic Hydrocarbon) growth.

This scheme is directly validated by a comparison with experimental data gathered in the research reactor described in Figure 6, A and B. The complexity of processes has necessitated the development of an instrumented reactor Figure 6A. It is a hot-wall tubular reactor with laminar flow. Feeding with source molecules occurs at the top, whereas the reaction gases are pumped at the bottom through the pressure regulator. All the characterizations have been made with pressures in the range of 0.5 to $10 \mathrm{kPa}$, temperatures from 900 to $1150{ }^{\circ} \mathrm{C}$, and residence times from $0.05 \mathrm{~s}$ to $10 \mathrm{~s}$.

The reactor can be coupled to a microbalance (Figure 6A) for the kinetic studies: the mass uptake is continuously registered versus time in different reactor conditions. The same reactor can also be equipped with a Fourier Transform Infra-Red spectrometer (FT-IR) to analyse the light species of the gaseous phase (Figure 6B). The reactor possesses also an outlet directly connected to a gas chromatograph (GC-MS). It is also possible to use plates to sample the heaviest species by condensation. This way, it is possible to know the composition of the gas phase versus the residence time in the hot zone. Finally, the structure of the deposit is directly analysed by TEM, by using a carbon grid as substratum in the hot zone.

Modelling may also take into account transport in the dead volume or coupling with diffusion within the preform porosity. The goal of these researches was to model the mass uptake in the fibrous preform for carbon/carbon composite disk processing. All these models were validated against experimental data.

\subsection{Multi-scale structure of pyrocarbons by Raman spectroscopy}

Pyrocarbons are not crystalline phases; they are said paracrystalline materials. ${ }^{12}$ To be complete, pyrocarbon structure has to be described at a nanometer range (also called structure) and at long range (texture). In order to discriminate and classify all the pyrocarbons, we have recently proposed to measure the crystalline defects of the lattice at short range and the anisotropy of the texture at long range. This can be done by optical
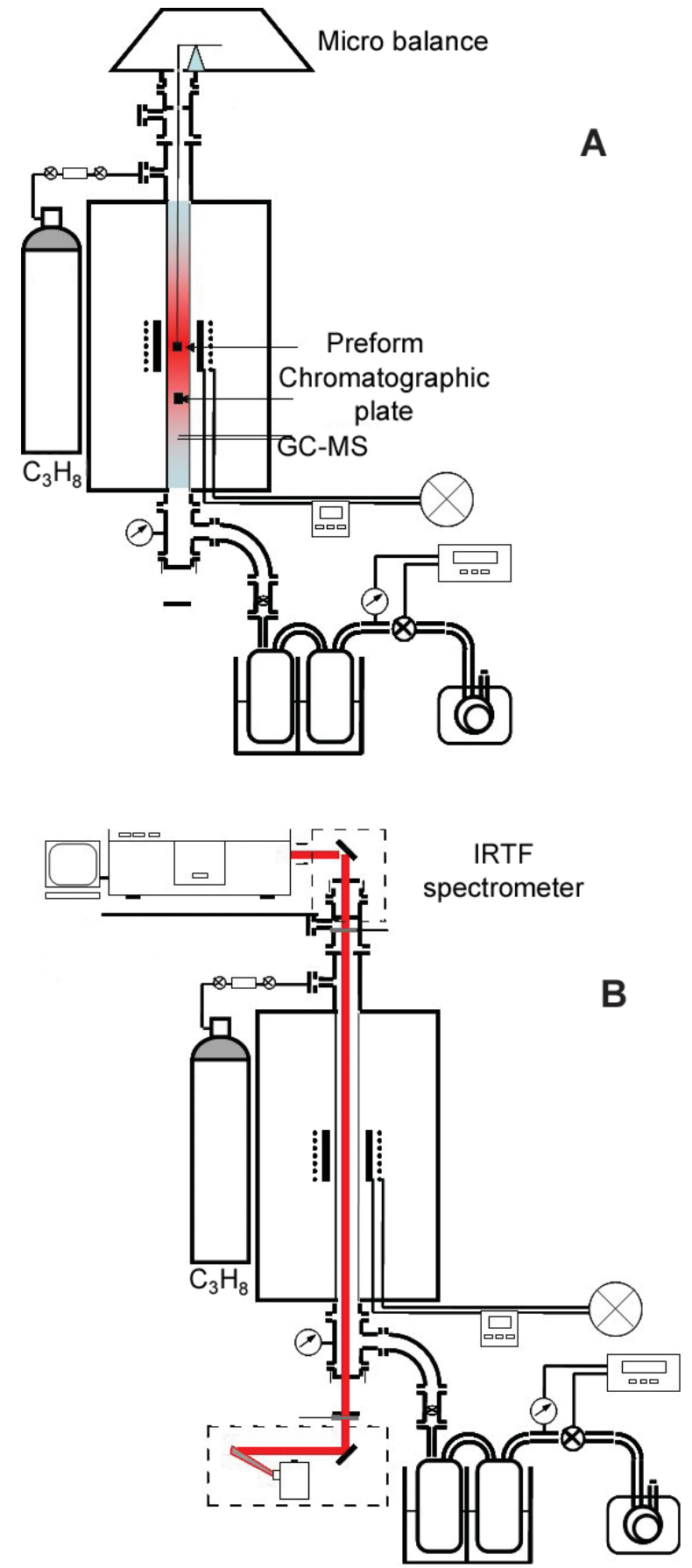

Figure 6. Experimental instrumented reactor to establish deposit kinetics (A) and existence diagram of deposit structures versus gaseous compositions (B). Adaptation from Reference 20.

measurement. ${ }^{13}$ In the present paper, we propose to acquire both measurements, by using Raman MicroSpectroscopy as shown in Figure $7 .{ }^{14}$ A first order Raman spectrum of graphitic carbon exhibits two main peaks: the G-band $\left(\mathrm{E}_{2 \mathrm{~g}}\right.$ mode of graphite) and the $\mathrm{D}$ band. These two modes correspond to the same optic phonon, LO and are polarized parallel to the graphene planes. The Raman diffused ray is also polarized 

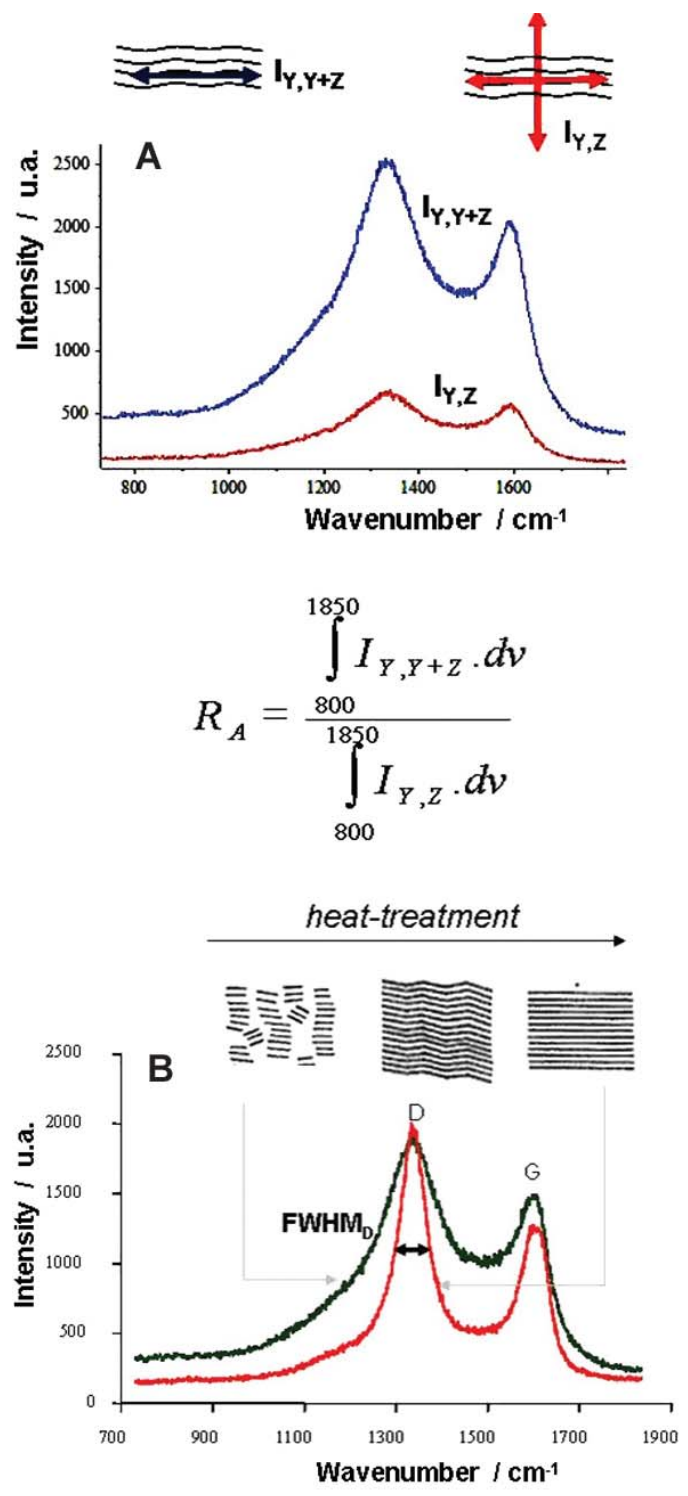

Figure 7. Polarised Raman spectroscopy: A) $R_{A}$, Raman anisotropy factor, is the integrated intensity measured under cross- polars divided by the intensity with the polarizer alone; B) Broadening of the D-band as a function of defects' density. Adaptation from Reference 20.

parallel to the graphene planes. By using a crossed analyser, it is possible to record the diffusion of disoriented layers with respect to the main anisotropic plane. The ratio of the respective intensities, without and with the analyzer (blue and red curve on Figure $7 \mathrm{~A}$, respectively) between 800 and $1850 \mathrm{~cm}^{-1}$ is used to define what we call the $\mathrm{R}_{\mathrm{A}}$ factor of the pyrocarbon texture.

For a long time, the D-band has been empirically connected to defects. The role of the defects in the broadening of the D-band is nowadays well understood, thanks to the 'double resonance' theory. ${ }^{15-16}$ On that basis we propose to quantify the graphene defects by measuring its broadening, corresponding to the LO phonon. The D-band was preferred because it is easily subtracted: its full width at half maximum $\left(\mathrm{FWHM}_{\mathrm{D}}\right)$ is inversely proportional to the life time of the phonon: the higher the defects density, the shortest the phonon's life time. As a matter of fact, FWHM $_{D}$ decreases as the heat-treatment temperature of the pyrocarbon increases as illustrated in the scheme of Figure 7B. For a homogeneous family of carbon, FWHM $_{\mathrm{D}}$ can be proposed to discriminate the amount of defects in the lattice. That was proposed to discriminate, with success, the structure of all the pyrocarbons known at that time. ${ }^{14}$

$\mathrm{FWHM}_{\mathrm{D}}$ is thus the key parameter for scattering the structural axis of the classification: ordinate in Figure 8. As for the abscissa, it is related to the texture or the anisotropy. This parameter can be measured by optical microscopy (i.e. Ae, the extinction angle), by TEM (OA, the orientation angle) ${ }^{14}$ or $R_{A}$ the Raman anisotropy factor. $R_{A}$ varies experimentally, from 2.2 for the isotropic pyrocarbons up to more than 8 for the highest anisotropic ones.

Each of the three growth mechanisms known so far, occupies one specific area in this diagram. Following the arrow which characterizes the increasing maturation of the gas phase, it is successively obtained: Rough Laminar pyrocarbon (RL), Dark laminar (DL) and Regerative Laminar (ReL). Smooth Laminar (SL) and Granular $(\mathrm{G})$ are intermediate structures.

\section{Definition of the Main Types of Pyrocarbon versus Growth Process}

\subsection{Rough Laminar pyrocarbon (LR)}

Rough Laminar pyrocarbon is very anisotropic. It forms by CVI at short residence time. This pyrocarbon grows following a heterogeneous mechanism, in infiltration exclusively. In this case, the intermediate species forming by cracking of the source molecule and infiltrated in the porosity are identified as small molecules, probably radicals. This mechanism, which involves chemisorption and dehydrogenation of the species, forms short but straight carbon layers, which easily pile one on the other (high $\mathrm{L}_{c}$, i.e., coherent length as measured by X-ray diffraction along the $\mathrm{c}$ direction). Amount of residual defects is low, anisotropy is high (see the high 001 orders in the diffraction pattern in Figure 8). The name was provided by the optical appearance of its rough Maltese-cross under crosspolars (see on Figure 9). 


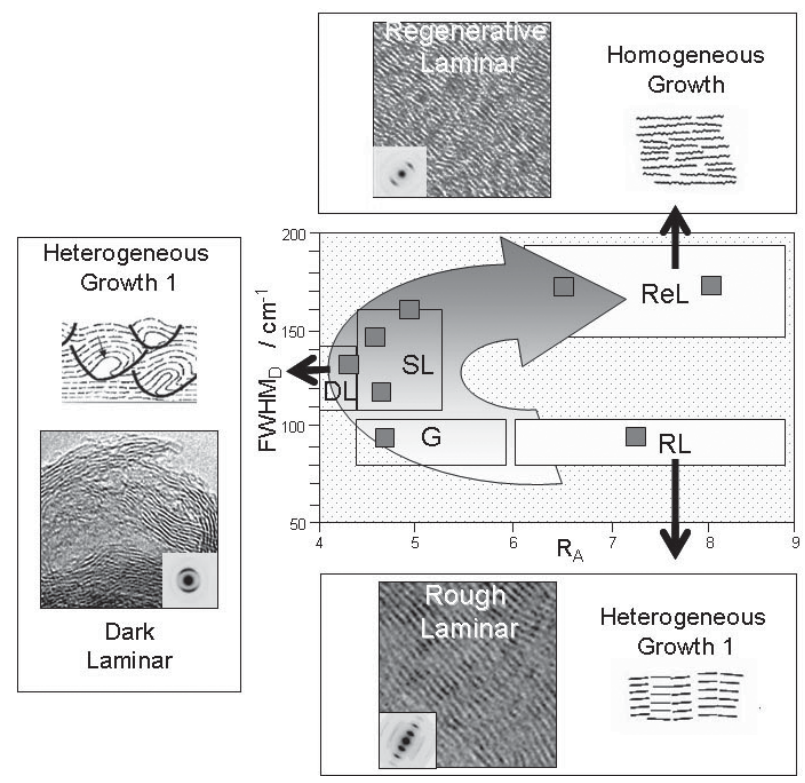

Figure 8. Classification of low temperature pyrocarbons: FWHM $_{\mathrm{D}}$, broadening of the Raman D-band $v s \mathrm{R}_{\mathrm{A}}$, the Raman anisotropy factor. The arrow indicates the increasing maturation of the gas phase. The three main pyrocarbon-growth-mechanisms are illustrated with their HR-TEM images in high resolution and electron diffraction. Adaptation from Reference 20.

\subsection{Regenerative Laminar (LRe)}

Regenerative Laminar was discovered very recently. ${ }^{17}$ This pyrocarbon is also very anisotropic (high $R_{A}$ ). Meanwhile, its lattice is seen to possess a high amount of defects as measured by the broadening of the Raman D-band: high FWHM $_{\mathrm{D}}$. Transmission electron microscopy (TEM) shows that layers are long, well oriented but comprising a high amount of defects. Regenerative Laminar pyrocarbon forms with a homogeneous growth mechanism. Residence time is long. Gaseous phase produces large PAH molecules (Polycyclic Aromatic Hydrocarbon), which deposit by physisorption on the growth surface. The low diffusivity and reactivity of these molecules on the surface, limit the perfection of the lattice (trapping a high amount of defects and hydrogen).

\subsection{Dark Laminar pyrocarbons $(D L)$}

Dark laminar pyrocarbons occupy the left of this diagram. They are weakly anisotropic, so they possess the lowest $R_{A}$ (see Figure 8). These pyrocarbons possess in the same time an intermediate value for $\mathrm{FWHM}_{\mathrm{D}}$. We have shown that the drop of anisotropy is related to the heterogeneous growth of long layers. In this case pentagons and heptagons are trapped in the hexagonal lattice. ${ }^{18}$ Layer distortions form $\Omega$-like features in the texture. This produces a structural porosity, which controls the drop in density and anisotropy.
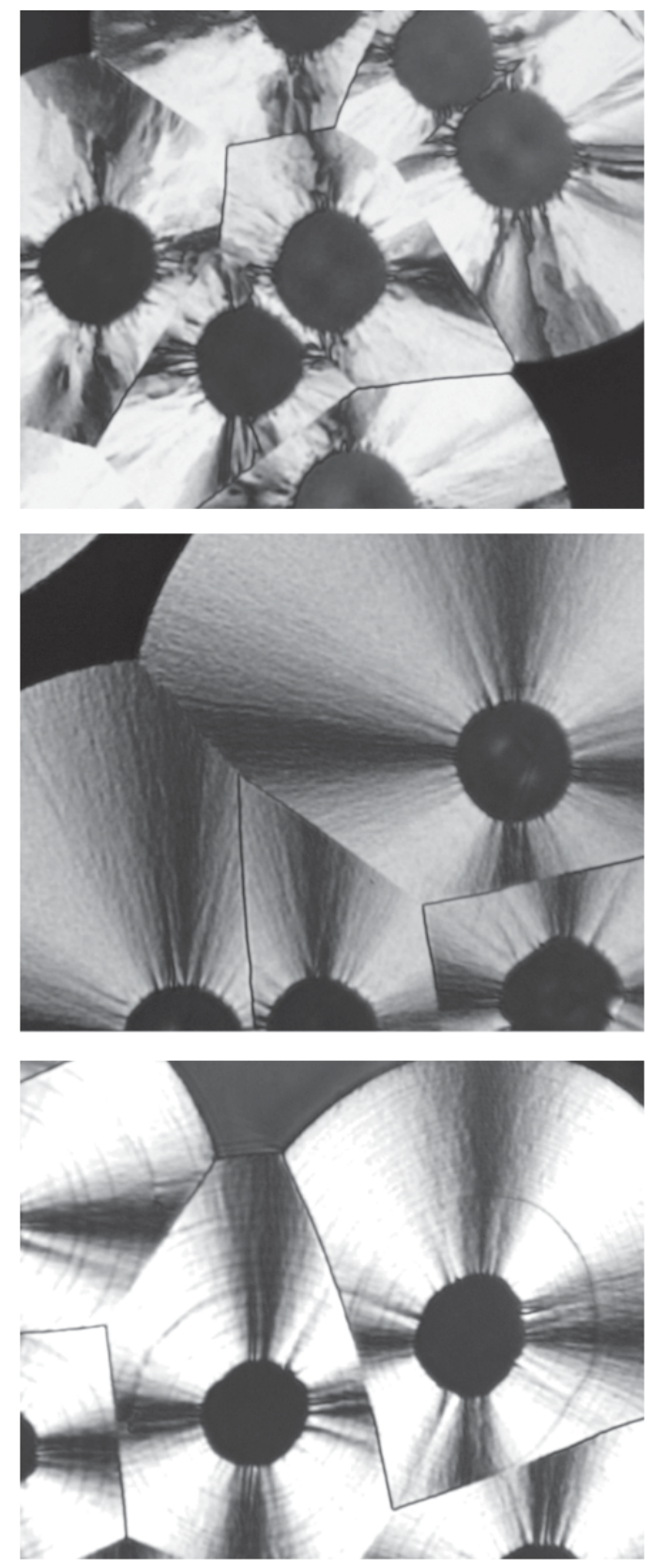

Figure 9. The three main types of pyrocarbon when deposited as a matrix in carbon/carbon composite, as seen by optical microscopy under cross-polars (objective $150 \times$ in water $n=1,5$ ). Top down: Rough Laminar, Dark Laminar and Regenerative Lamina pyrocarbons (bare is $10 \mu \mathrm{m}$ ).

\subsection{Smooth laminar and Granular pyrocarbons}

The 3 previous types are supposedly corresponding to a single growth mechanism. In-between these three basic types appear transitions. The strongest hypothesis on this matter is to consider that nature of species that form in the gas phase is controlling one (or two) mechanism(s). Depending on the optical appearance of these pyrocarbons it is possible to distinguish Granular $(\mathrm{G})$ pyrocarbons and a very broad family known for a long time: Smooth Laminar pyrocarbons (SL). 


\section{Conclusions}

Pyrocarbon is a family of carbon materials that contains up to 5\% of hydrogen and are deposited following various mechanisms. These mechanisms control the structure and texture and thereafter the density as well as many properties, like heat conductivities, elastic modulus ${ }^{19}$ toughness, etc varying in a broad range of values: for example, density goes from 1 to 2.2 .

The breakthrough in the understanding of the pyrocarbon growth could be advantageously related to the Raman data. In this way, a rationalisation of this complex field could be obtained.

\section{Acknowledgments}

The "Conseil Régional de la Région d'Aquitaine" is acknowledged for the different grants all along this project. The authors wish to thank Pr Roger Naslain for his support as well as René Pailler, Jacques Thébault and Christian Robin-Brosse for their respective interest in this project. All the students who have participated to this project are associated to this paper: Cédric Descamps, Pascal Dupel, Olivier Féron, Damien Feuillu, Arnaud Fillion, Jérome Lavenac, Hélène Le Poche, Arnaud Mouchon, Nicolas Reuge, Béatrice Trouvat and Jean-Marie Vallerot.

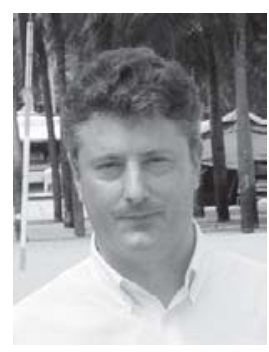

Xavier Bourrat (Université Bordeaux

- France): Xavier Bourrat received the French State Doctorate in Materials Science in 1987, studying conductive blacks by TEM, ESR and fractal modeling. He previously received his Ph.D. in Materials Science working with Dr. Agnes Oberlin on thermal evolution of petroleum asphaltenes. Having passed the CNRS national entrance examination, he held a post-doctoral position at the Fiber Research Division of the Du Pont Experimental Station in 1988. He received the international Schunk Award '96 for this work: "Evidence of Disclinations in Mesophase-Pitchbased Carbon Fibers". Currently he is studying refractive carbon and biomineralization in Orleans University, France. He is author or co-author of 5 patents and over 190 publications in journals, books and conferences.

\section{References}

1. Tombrel, F.; Rappeneau, F. In Les Carbones; Pacault, A., ed., Masson: Paris, 1965, p. 783

2. Vignoles, G. L.; Langlais, F.; Descamps, C.; Mouchon, A.; Le Poche, H.; Reuge, N.; Bertrand, N.; Surf. Coat. Technol. 2004, 188-189, 241.

3. Delhaès, P.; Carbon 2002, 40, 641.

4. Savage, G.; Carbon-Carbon Composites, Chapman and Hall: London, 1993.

5. Bokros, J. C. In Chemistry and Physics of Carbon; Walker Jr., P. L., ed., CRC: New York, NY, 1969, vol.5, p.1.

6. Houdayer, M.; Spitz, J.; Trau Van, D.; Brevet français 81 22163, 1981.

7. Dupel, P.; Pailler, R.; Bourrat, X.; Carbon 1995, 33, 1193.

8. Leutard, D.; Vignoles, G. L.; Lamouroux, F.; Bernard, B.; J. Mater. Synth. Process. 2001, 9, 259.

9. Golecki, I.; In World of Carbon; Delhaès, P., ed., Taylor and Francis: London, UK, 2003, vol. 2, p.112.

10. Hüttinger, K.J.; In World of Carbon; Delhaès, P., ed., Taylor and Francis: London, UK, 2003, 2, 75.

11. Descamps, C.; Vignoles, G. L.; Feron, O.; Langlais, F.; Lavenac, J.; J. Electrochem. Soc. 2001, 148, C695.

12. Bourrat X. In Science of Carbon Materials; Marsh, H.; Rodriguez-Reinoso, F., eds., Universidad de Alicante, 2000, p.1.

13. Vallerot, J.-M.; Bourrat, X.; Carbon 2006, 44, 1565.

14. Vallerot, J.-M.; Bourrat, X.; Mouchon, A.; Chollon, G.; Carbon 2006, 44, 1933.

15. Thomsen, C.; Reich, S.; Phys. Rev. B: Condens. Matter Mater. Phys. 1999, 59, 6585.

16. Saito, R.; Jorio, A.; Souza-Filho A .G. T.; Grueneis, A.; Pimenta, M. A.; Dresselhaus, G.; Dresselhaus, M. S.; Physica 2002, $B 323,100$.

17. Bourrat, X.; Fillion, A.; Naslain, R.; Chollon, G.; Brendlé, M.; Carbon 2002, 40, 2931.

18. Bourrat, X.; Lavenac, J.; Langlais, F.; Naslain, R.; Carbon 2001, 39, 2376

19. Sauder, C.; Lamon, J.; Pailler, R.; Carbon 2005, 43, 2054.

20. Bourrat, X.; Vallerot, J.-M.; Langlais, F.; Vignoles, G.L.; L'Actualité Chimique 2006, 295-296, 57.

Received: March 21, 2006

Published on the web: September 20, 2006 